\title{
EKOFEMINISME TOKOH PEREMPUAN DALAM NOVEL CHEMISTRY CINTA DI WAKATOBI KARYA DEDI OEDJI
}

\author{
Nursyamsia ${ }^{a},{ }^{*}$ Sakaria ${ }^{\text {b, }}{ }^{*}$ Faisal $^{\mathrm{c}}$ \\ aBalai Bahasa Sulawesi Tengah \\ a Jalan Untad 1, Bumi Roviga, Tondo, Palu, Indonesia \\ ${ }^{b, c}$ Fakultas Bahasa dan Sastra Universitas Negeri Makassar \\ b, c Jalan Daeng Tata Raya No. 27, Makassar, Indonesia \\ aPos-el: nursyamsimuharram@gmail.com \\ bos-el:sakaria@unm.ac.id \\ cPos-el: faisalcoker@gmail.com
}

\begin{abstract}
Abstrak
Ketidakadilan terhadap perempuan dalam lingkungan menyangkut eksploitasi yang dilakukan oleh manusia terhadap alam. Secara konseptual, isu feminis perempuan memiliki relasi terhadap isu ekologis. Novel Chemistry Cinta di Wakatobi karya Dedi Oedji mengisahkan kehidupan komunitas Nelayan Bajo berbagai masalah ekologi di Wakatobi. Penelitian ini bertujuan mengkaji relasi alam dan perempuan dalam novel Chemistry Cinta di Wakatobi berdasarkan perspektif teori ekofeminisme sosialis Keren J Werren. Penelitian ini adalah penelitian deskriptif kualitatif. Data penelitian bersumber pada novel Chemistry Cinta di Wakatobi. Data penelitian dikumpulkan dengan menggunakan teknik baca dan teknik catat. Selanjutnya, data yang terkumpul dianalisis berdasarkan kajian ekofeminisme sosialis. Hasil penelitian menunjukkan bentuk relasi antara alam dan perempuan Wakatobi tercermin pada tokoh Anisa, Wa Dambe, dan Wa Tanihi. Relasi yang terjalin dalam bentuk konservasi atau pemberian perlindungan alam, pemanfaatan dan pelestarian terhadap alam menjaga ketahanan pangan, dan penguatan akses perempuan dalam pemanfaatan sumber daya alam.
\end{abstract}

Kata Kunci: ekofeminisme, tokoh perempuan, Chemistry Cinta di Wakatobi

\section{Ecofeminism Of Women In The Novel Chemistry Cinta Di Wakatobi By Dedi Oedji}

\begin{abstract}
Injustice towards women in the environment concerns the exploitation by humans of nature. Conceptually, women's feminist issues have a relationship to ecological issues.The novel Chemistry Cinta di Wakatobi by Dedi Oedji tells the story of the Bajo fishing community of various ec ological problems in Wakatobi. This study aims to examine the relationship between nature and women in the novel Chemistry Cinta di Wakatobi based on the perspective of Keren $J$ Werren socialist ecofeminism theory. This research is a qualitative descriptive study. The research data comes from the novel Chemistry Cinta di Wakatobi. The research data were collected using reading and note taking techniques. Furthermore, the collected data were analyzed based on studies of socialist ecofeminism. The results showed that the form of the relationship between nature and Wakatobi women is reflected in the figures of Anisa, Wa Dambe, and Wa Tanihi. Relationships that exist in the form of conservation or provision of protection of nature, utilization and preservation of nature maintain food security, and strengthen women's access to the use of natural resources.
\end{abstract}

Keywords: ecofeminism, female characters, Chemistry Cinta di Wakatobi

\section{PENDAHULUAN}

Karya sastra merupakan gambaran tentang kehidupan yang ada dalam masyarakat. Kehidupan sosial, kehidupan individu, hingga keadaan psikologis tokohya tersirat dalam karya sastra. Karya sastra lahir tidak terlepas dari peran penting penciptanya. Akhir-akhir ini bermunculan pencipta karya sastra, seiring dengan populernya isu-isu yang berkembang di masyarakat mengenai wacana ekologi. Permasalahan ekologi menarik perhatian khusus para pencipta dan kritikus sastra. Bagi pencipta karya sastra, wacana ekologi dapat dijadikan sebagai tema dan latar fisik penciptaan karya sastra. Oleh karena itu, saat ini banyak tercipta berbagai karya sastra yang bercorak dan bernuansa ekologi. Seperti halnya novel Chemistry Cinta di Wakatobi karya Dedi 
Oedji mengangkat tema dan latar fisik mengenai kehidupan komunitas nelayan Bajo di Wakatobi.

Novel Chemistry Cinta di Wakatobi mengisahkan perjuangan aktivis kampus dalam melakukan pengumpulan data untuk menyelesaikan tugas akhir skripsi. Latar fisik penceritaan menampilkan sisi keindahan alam Wakatobi dan berbagai masalah ekologi termasuk eksploitasi alam bawah laut, perjuangan perempuan Wakatobi untuk melawan stigma yang telah tertanam dalam kulturnya, dan pembuktian bahwa wanita bukan makhluk kelas dua dan inferior terhadap kaum patriarki. Selain itu, digambarkan pula perjuangan perempuan suku Bajo yang ingin membawa perubahan terhadap kaumnya dengan tetap menjaga alam bawah laut Wakatobi tanpa merusak isinya.

Ekofeminisme hadir karena adanya sebuah gerakan atau teori yang berhubungan dengan perempuan dan alam (Wiyatmi \& Swatikasari, 2017). Perempuan menyadari bahwa adanya kuasa patriarki terhadap perempuan dan dominasi terhadap alam yang dibuktikan dengan kerusakan lingkungan. Hal ini, menunjukkan bahwa adanya kuasa patriarki tidak hanya merusak perempuan, melainkan juga merusak lingkungan hingga muncullah pandangan bahwa adanya ikatan khusus antara perempuan dengan alam. Ketidakadilan terhadap perempuan dalam lingkungan awal mulanya berangkat dari adanya ketidakadilan yang dilakukan oleh manusia terhadap alam (Wulan, 2007).

Ekofeminisme berpandangan bahwa modus berpikir patriarki yang hierarkis, dualistik, dan opresif telah merusak perempuan dan alam (Warren, 1987). Pandangan ini, dinyatakan sebagai varian ekofeminisme yang bernuansa sosial (ekofeminisme sosialis) oleh Keren J Werren. Ekofeminisme sosialis menititikberatkan kajian terhadap ketidakadilan terhadap perempuan dalam lingkungan yang menyangkut ketidakadilan yang dilakukan oleh manusia terhadap alam. Sosok perempuan selalu dihubungkan dengan alam, maka secara konseptual terdapat relasi antara isu feminis dan ekologis. Pada realitasnya, perempuan memang selalu diintimidasi, dikuasai, dan digarap.

Beberapa penelitian yang mengkaji perspektif ekofinisme dalam karya sastra bergenre prosa fiksi, antara lain Hardiningtyas (2016) mengkaji resistensi perempuan Papua di lingkungannya dalam roman Isinga karya Dorotea Rosa Herliany ditinjau dari perspektif ekofeminisme sosialis Vanda Shiva. Perjuangan perempuan Papua dalam membebaskan diri dari kekerasan, terutama yang bersumber dari struktur dan budaya masyarakat, kondisi alam, dan adatnya telah melahirkan resistensi posisi perempuan merupakan simpulan hasil penelitian yang diperoleh. Selanjutnya, Solichin (2018) melakukan kajian ekofeminisme dalam novel Tanah Tabu dengan sudut pandang antroposentrisme kapitalis. Peneliti berkesimpulan bahwa kesiagaan tokoh perempuan dalam mempertahankan hidup dan alamnya mengindikasikan usahanya dalam mensinergikan prinsip feminis dengan prinsip ekologi yang melahirkan gerakan kaum perempuan berupa naluri empati, belas kasih, solidaritas, dan melestarikan ekosistem alam.

Penelitian tentang relasi perempuan dan alam dengan memanfaatkan teori ekofeminisme pada karya sastra bergenre prosa fiksi masih langka. Oleh karena itu, penelitian ini bertujuan mengkaji relasi alam dan perempuan dalam novel Chemistry Cinta di Wakatobi. Adapun perspektif teori ekofeminisme sosialis Keren J. Werren akan dipergunakan untuk membahas karya sastra yang diteliti. Hasil penelitan diharapkan dapat memberikan gambaran mengenai relasi alam dan perempuan Wakatobi serta melengkapi kajian-kajian penelitian yang relevan. 


\section{TEORI}

Ekofeminisme adalah istilah dari perspektif feminis tentang alam yang terkait dengan isu lingkungan dan gender (Hardiningtyas, 2016). Istilah tersebut, pertama kali digunakan oleh Francoise D'Eaubonne dalam beberapa aksi perusakan lingkungan yang dipicu oleh bencana ekologi. Ekofeminisme merupakan gagasan lama yang muncul dari berbagai gerakan sosial-feminis, perdamaian dan ekologi pada akhir 1970-an dan awal 1980-an (Mies dkk, 2014).

Ekofeminisme muncul sebagai bentuk kritik terhadap arah perkembangan ekologi dunia yang semakin memburuk (Setyorini, 2017). Salah satu kritik keras ekofeminisme adalah gerakan feminisme modern, terutama feminisme liberal dan feminisme sosialis/marxisme. Teori feminis tersebut berpandangan bahwa individu adalah makhluk otonom yang independen dari pengaruh lingkungannya dan berhak menentukan gaya hidupnya sendiri. Sedangkan teori ekofeminisme memiliki sudut pandang yang berbeda. Teori ini memandang individu lebih komprehensif sebagai makhluk yang terikat dan berinteraksi dengan lingkungannya.

Ekofeminisme merupakan bagian dari sudut pandang feminis yang mengkaji gerakan perempuan dengan gerakan ekologi berdasarkan teori atau gerakan etika yang ingin mendobrak etika antroposentrisme (Solichin, 2018). Antroposentrisme muncul dari hasrat manusia yang menginginkan kemakmuran. Jika hasrat tersebut tidak terpenuhi, manusia mencari cara untuk menjadikan alam sebagai pemenuhan hasrat. Bukan hanya sekadar antroposentrisme, ekofeminisme bahkan secara lebih khusus melawan etika androsentrisme, yaitu etika lingkungan hidup yang berpusat pada laki-laki serta memiliki cara pandang yang mengutamakan dominasi, eksploitasi, dan manipulasi terhadap lingkungan.
Pada dasarya ekofeminisme merupakan aliran pemikiran dan gerakan dalam feminisme yang menghubungkan dominasi patriarki atas alam dan merupakan bentuk penindasan terhadap perempuan (Wuriyani, 2017). Isu ekologis tentunya tidak lepas dari kajian ekofeminisme, isu yang menyangkut opresi terhadap alam yang melibatkan perempuan di dalamnya. Opresi dalam hal ini, tentu saja dilakukan oleh kaum patriarki yang cenderung ingin bersifat superior dibanding perempuan (Wiyatmi \& Swatikasari, 2017).

Ekofeminisme dapat digolongkan ke dalam feminisme gelombang ketiga bersama dengan feminisme multikultural dan global (Novitasari, 2018). Sehubungan dengan hal itu, ekofeminisme tidak hanya berusaha untuk menunjukkan hubungan antara semua bentuk opresi manusia, tetapi juga memfokuskan pada usaha manusia dikaitkan untuk mendominasi dunia bukan manusia, atau alam. Perempuan secara kultural dikaitkan dengan alam, sehingga ekofeminis berpendapat jika ada hubungan konseptual, simbolik, dan linguistik antara feminis dan isu ekologi. Sementara itu, jika dilihat dari sudut pandang ekologi sastra, ekofeminisme merupakan perluasan objek kajian dari ekokritik yang memiliki fokus terhadap alam secara fisik kemudian berkembang ke arah kajian lingkungan kebudayaan khususnya gender (Tong, 2008).

Karen J. Warren merupakan tokoh penganut ekofeminisme sosialis yang berasumsi, jika perempuan meminimalkan hubungan mereka dengan alam yang dikonstruksikan secara sosial dan dipaksakan secara ideologis, perempuan akan terus menerus tersubordinasi oleh laki-laki, begitu juga alam akan tersubordinasi oleh kebudayaan (Sudikan, 2016). Selanjutnya, (Warren, 1987) membagi asumsi dasar ekofeminisme menjadi empat bagian, yaitu (1) ada keterkaitan penting antara opresi terhadap perempuan dan opresi terhadap alam; (2) pemahaman terhadap alam 
dalam keterkaitan ini adalah penting untuk mendapatkan pemahaman yang memadai atas opresi terhadap perempuan dan opresi terhadap alam; (3) teori dan praktik feminis harus memasukkan perspektif ekologi, dan (4) pemecahan masalah ekologi harus menyertakan perpektif feminis..

\section{METODE}

Penelitian ini adalah penelitian deskriptif kualitatif, karena data yang digunakan merupakan data kata-kata dan kalimat-kalimat. Penelitian kualitatif merupakan penelitian yang bermaksud untuk memahami fenomena tentang apa yang dialami subjek penelitian, misalnya perilaku, persepsi, motivasi, tindakan dan lain-lain, secara holistik dan dengan cara deskripsi dalam bentuk katakata dan bahasa, pada suatu konteks khusus yang alamiah dan dengan memanfaatkan berbagai metode alamiah (Moleong, 2019). Adapun sumber data dalam penelitian ini adalah novel Chemistry Cinta di Wakatobi karya Dedi Oedji yang diterbitkan oleh PT. Gramedia Jakarta.

Teknik pengumpulan data yang digunakan dalam penelitian ini adalah teknik baca dan teknik catat. Langkah- langkah pengumpulan data dilakukan dengan membaca novel Chemistry Cinta di Wakatobi secara berulang-ulang dari awal sampai akhir dan mencatat kata atau kalimat yang berhubungan dengan fokus penelitian. Selanjutnya dilakukan analisis data dengan cara membuat deskripsi secara detail data yang berupa kutipan-kutipan paragraf dan dialog mengenai permasalahan ekofeminisme dalam novel Chemistry Cinta di Wakatobi. Kemudian menganalisis dan mengembangkannya dengan memberikan penafsiran berdasarkan kajian ekofeminisme sosialis Karen J. Warren sesuai dengan masalah penelitian.

\section{HASIL DAN PEMBAHASAN}

Ekofeminisme tokoh perempuan yang terbangun dalam novel Chemistry Cinta di Wakatobi merupakanrelasi yang terkait peran perempuan dalam konservasi alam dalam bentuk perlindungan, pemanfaatan dan pelestarian sumber daya alam, menjaga ketahanan pangan, dan akses dalam memanfaatkan sumber daya alam.

\section{Relasi Alam dan Perempuan dalam Hal Konservasi Alam}

Relasi alam dan perempuan dalam hal konservasi alam, menurut pemikiran Keren J. Werren termasuk dalam pelibatan pemikiran feminis dalam menyelesaikan masalah ekologi, konservasi atau upaya pelestarian, pemanfaatan, dan pelindungan terhadap alam.

Kutipan data (1) menyatakan bentuk pelindungan terhadap alam bawah laut. Tokoh perempuan yang melakukan tindakan konservasi atau pelindungan terhadap alam bawah laut Wakaktobi adalah Wa Dambe. Perempuan ini tidak terbiasa bahkan cenderung menolak menggunakan alat selam modern untuk melakukan snorkeling atau diving.

(1). "Kalau menggunakan alat selam modern malah bikin aku jadi kaku, bahkan tidak bisa berenang sama sekali. Aku tidak bisa menggunakan kaca mata seperti yang dipakai Bagas. Apalagi menggunakan sepatu yang mirip sirip ikan duyung itu, “ jawab Wa Dambe

Polos."(Oedji, 2012).

Kutipan data (1), secara sadar atau tidak, Wa Dambe telah memberikan pelindungan terhadap ekosistem bawah laut agar tetap terjaga kelestariannya tanpa banyak mendapat perusakan secara sengaja ataupun tak sengaja oleh penikmat bawah 
laut dengan segala kecanggihan teknologi saat ini. Kalimat "kalau menggunakan alat selam modern malah bikin aku jadi kaku bahkan tidak bisa berenang sama sekali” merupakan pernyataan Wa Dambe yang menolak menggunakan kacamata modern, masker, fin kaki katak dan tabung gas. Wa Dambe lebih memilih menggunakan kacamata selam tradisional berbingkai kayu yang di tengahnya melingkar dua kaca bundar seukuran bola mata. Hal ini dilakukan sebagai bentuk penyelerasan dengan alam, menikmati alam tanpa menimbulkan ancaman perusakan. Menjaga keseimbangan alam bawah laut dengan berusaha berhati-hati dalam menikmati dan memanfaatkannya merupakan salah satu bentuk konservasi terhadap alam agar nantinya keindahan bawah laut dan ketersediaan sumber daya alam tetap dapat terpenuhi hingga masa yang akan datang.

Bentuk lain dari relasi alam dan perempuan tercermin ketika tokoh Anisa mampu untuk memaknai kejadian alam dengan melibatkan rasa feminitas dalam dirinya. Sifat-sifat feminis dalam hal ini lemah lembut dan memiliki rasa kasih, kedamaian, dan kebersamaan tergambar pada kutipan data (2) dan (3) berikut ini.

(2). "Bisa nggak sih makan nggak pake bercanda? "Jadi nggak fokus nih nikmatin seafood."(Oedji, 2012).

(3). "Soalnya aku udah lama banget nggak nikmatin seafood di Wakatobi. Citarasa dagingnya beda banget tau sama yang di Jakarta (Oedji, 2012)" .

Kutipan data (2) dan (3) dituturkan tokoh Anisa ketika di pantai di kawasan Wakatobi pada saat hendak menyeberang ke Kaledupa bersama Bagas. Pada kedua kutipan data tersebut, terdapat kata menikmati seafood yang menggambarkan bahwa bentuk konservasi yang dilakukan tokoh Anisa dalam hal memanfaatkan alam secara bijak sekaligus melestarikan kekayaan olahan makanan yang berasal dari alam yang tidak kalah dari olahan makanan cepat saji. Pengetahuan Anisa tentang pemanfaatan bahan alam menjadi olahan makan yang lezat juga tampak pada kutipan data (4) berikut ini:

(4). Makanya buruan sini. Nasi kuningnya enak tau. Khas Wakatobi banget. Berasnya diolah dengan santan kental, parutan kunyit dan daun pandan. Lauknya ikan goreng cakalang yang diberi bumbu sambal tomat terus dibungkus dengan daun pisang segar. (Oedji, 2012).

Pada kutipan data (4), tokoh Anisa memberikan penghargaan dan pujian terhadap hasil olahan bahan alam, berupa beras, santan yang berasal dari kelapa, kunyit, daun pandan, ikan serta daun pisang. Jika manusia mampu menjalin hubungan baik dengan alam maka ketersediaan pangan akan tercukupi, dan tidak terkuasai oleh kapitalis.Ketika pangan terkuasai oleh kapitalis, tugas perempuan akan semakin sulit dalam menjaga ketahanan pangan keluarga. Di sisi lain alam pun memperoleh dampak positif. Penggunaan bahan makanan atau kemasan makanan yang tidak ramah lingkungan dan sulit untuk terurai, dapat menyebabkan keseimbangan ekosistem terganggu.

Tokoh lain yang mampu memanfaatkan sisi feminisitas dan pengalaman dalam dirinya sebagai perempuan Bajo dalam membaca tanda- 
tanda alam adalah Wa Dambe. Wa Dambe mampu untuk memperkirakan jarak dan waktu tempuh perjalanan laut dan mahir mengemudikan transportasi laut, bahkan membaca rasi bintang, tampak pada kutipan data (5), (6), dan (7) berikut ini.

(5). Esok paginya, selesai membereskan pekerjaan dapur, Wa Dambe kembali bersiapsiap menjadi driver perahu mesin tempel menemani Bagas mengunjungi pulau Hoga yang terletak di sebelah timur pulau Kaledupa. Menurut Wa Dambe jarak Kaledupa ke pulau Hoga bisa ditempuh kurang lebih 20 menit. (Oedji, 2012).

(6). Tapi itu kalau misalnya tidak besar ombaknya, Wa Dambe buru-buru meralat informasinya. Dengan cekatan kakinya melangkah dari dermaga ke badan perahu. Kain sarung yang dikenakannya seolah tak menjadi penghalang keluesannya bergerak. (Oedji, 2012).

(7) "Wa Dambe mengajarkan bagaimana orang Bajo membaca rasi bintang dan menjadikan rasi bintang itu sebagai kompas ketika orang Bajo berada ditengah laut. Termasuk bagaiaman orang bajo memahami cuaca, angin, dan arus laut yang selalu menjadi bagian dari kehiduapan kaum gipsi laut".(Oedji, 2012)

Situasi pada kutipan data (5) dan (6), terjadi saat Wa Dambe akan menemani
Bagas ke pulau yang terletak sedikit jauh dari daratan Kaledupa, yaitu Pulau Hoga, sebuah tempat snorkeling dan diving yang indah. Pada kedua kutipan tersebut, tergambarkan bahwa perempuan suku Bajo diketahui memiliki hubungan kedekatan dengan alam. Kedekatan itu tampak ketika Wa Dambe mampu untuk memperkirakan jarak tempuh, dan kondisi perairan yang tampak pada kalimat Kaledupa ke pulau Hoga bisa ditempuh kurang lebih 20 menit.

Selain itu, pada kutipan data (7) digambarkan bahwa pertalian antara alam dan perempuan sangat erat. Kemampuan membaca rasi bintang untuk penunjuk arah, cuaca dan angin dapat memberikan bantuan terhadap kelangsungan hidup manusia terlebih pada perempuan. Pengetahuan tersebut, menjadikan perempuan mampu mengatur strategi untuk mengelola keuangan agar mencukupi hingga musim berganti dan kreatif memanfaatkan segala hal pada alam ketika cuaca sedang buruk. Timbal baliknya dengan alam adalah dengan kemampuan membaca kode dari alam maka perempuan akan senantiasa memperlakukan alam sesuai dengan kode atau tanda yang diberikan agar keseimbangan ekosistem tetap terjaga. Hal ini merupakan salah satu bentuk konservasi alam. Sesuai dengan pendapat Keren J. Warren yang mengharapkan pelibatan aspek feminisme dalam pemecahan masalah ekologi begitupun sebaliknya.

\section{Peran Perempuan dalam Menjaga Ketahanan Pangan}

Bukan hanya bentuk konservasi, relasi alam dan perempuan juga tercermin pada peran perempuan dalam menjaga ketahanan pangan. Ketahanan pangan yang dimaksud dalam novel Chemistry Cinta di Wakatobiadalah peran perempuan dalam memastikan bahwa alam dipergunakan 
untuk memenuhi kebutuhan keluarga. Hal ini sejalan dengan pendapat Keren J. Warren bahwa persoalan feminisme dapat diselesaikan dengan melibatkan aspek ekologi. Peran perempuan dalam menjaga ketahanan pangan tampak pada kutipan data (8) berikut ini.

(8). Tapi perempuan itu mengelak, “eits...eits...sebentar biarkan aku letakkan gelasgelas berisi es kelapa muda kesukaanmu ini ke meja dulu. Baru setelah itu kamu boleh memelukku sepuasnya (Oedji, 2012).

(9). Ternyata Wa Dambe telah ada di belakangnya. Sepertinya ia barusan dari pasar karena menenteng keranjang belanjaan. (Oedji, 2012).

(10). "Tadi pagi Ibu Anisa baru memberitahu soal ini boleh aku kesana setelah menyelesaikan kerjaan dapur dulu?" (Oedji, 2012).

(11). "Sama-sama, Aku masuk dapur dulu ya. Sudah makin sore, “ pinta Wa Dambe akhirnya. Buru-buru ia melangkah masuk ke rumah. (Oedji, 212).

(12). Bagas menyandarkan punggung di dinding ruang depan sambil melirik hidangan di loyang yang baru saja diletakkan Wa Dambe di atas lantai ruang depan. Hemm... ikan kuah kuning, kerang congkel rebus, duri babi bakar dan sebuah makanan padat putih mirip tumpeng" (Oedji, 2012).

Kutipan data (8) sampai (12) mengisyaratkan relasi atau keterkaitan penting perempuan dalam menjaga ketahanan pangan keluarga. Pada data (8) dan (12), Wa Dambe memperlihatkan kebolehannya dalam menyajikan makanan dan minuman yang berasal dari bahan alam. Minuman yang dimaksud adalah olahan air buah kelapa, olahan hasil laut ikan, kerang dan duri babi serta olahan hasil bumi yaitu ubi yang dibuat kasuami. Pada kutipan data (9), (10), dan (11), peran sebagai penyedia makanan, memberikan gambaran mengenai bentuk tanggungjawab seorang perempuan dalam menjaga ketahanan pangan keluarga. Menjaga ketahanan pangan juga merupakan daya kreatif dari perempuan yang berelasi dengan alam, hasil alam kemudian diolah sedemikian rupa untuk menghasilkan sajian yang lezat. Kekreatifan yang dimaksud adalah penyesuaian perempuan yang mampu mengenali kandungan bahan makan, seperti karbohidrat pada nasi yang sama dengan yang terkandung pada olahan ubi yang oleh masyarakat Bajo sebut kasuami (makanan padat mirip tumpeng). Perempuan mengusahakan pelestarian ekologi melalui pemenuhan kebutuhan dari alam dan menghasilkan nafkah secara diam-diam.

\section{Akses dalam Memanfaatkan Sumber Daya Alam}

Bentuk lain relasi alam dan perempuan juga termasuk dalam pemanfaatan sumber daya alam. Berbagai hal di alam ini telah disediakan untuk memenuhi kebutuhan manusia. Hal ini kemudian membutuhkan sikap arif dan bijaksana manusia dalam memanfaatkan alam secara tidak sewenang-wenang, agar keseimbangan ekosistem tetap terjaga. 
pasar Kaledupa untuk di jual.

(Oedji, 2012)

Kerajinan yang dimaksudkan dalam kutipan data (15) dan dipertegas pada kutipan data (17) di atas adalah anyaman yang terbuat dari bahan alam berupa daun nipah yang mampu menghasilkan aneka benda yang berguna berupa topi, tikar bahkan tas. Kerajinan tersebut di buat oleh Nenek dari Wa Dambe bernama Wa Tanihi. Perempuan tua yang buta dan tidak dapat berbahasa Indonesia seperti yang di sebutkan pada kutipan data (16). Hal ini lagilagi sesuai dengan pemikiran Keren J. Warren yang menganjurkan untuk mengatasi masalah kaum feminis harus melibatkan ekologi. Pemahaman terhadap pemanfaatan alam tentu dapat memberikan keseimbangan ekosistem dan kesetaraanpun tercapai. Kesimbangan ekosistem yang dimaksud adalah ketika tidak ditemukan hal yang berlebihan pada salah satu lini kehidupan, termasuk pemanfaatan limbah daun nipah. Teori ekofeminisme mengedepankan peran perempuan untuk yang lebih "peka" dan "dekat" dengan alam. Masyarakat yang menjadikan alam dan tanah sebagai sumber kehidupan, hubungan yang tercipta tidak sekadar menguntungkan sebelah pihak saja, tetapi hubungan yang lebih intim antara alam dan masyarakatnya.

\section{PENUTUP}

dalam novel Chemistry Cinta di Wakatobikarya Dedi Oedjidalam bentuk relasi antara alam dan perempuan Wakatobi tercermin pada tokoh Anisa, Wa Dambe, dan Wa Tanihi. Relasi yang terjalin dalam bentuk konservasi atau pemberian perlindungan alam, pemanfaatan dan pelestarian terhadap alam menjaga ketahanan pangan, dan penguatan akses perempuan dalam pemanfaatan sumber daya alam.

Konservasi atau pemberian pelindungan alam dilakukan tokoh $\mathrm{Wa}$ Dambe dengan tindakan menolak menggunakan alat selam modern dalam melakukan snorkeling atau diving. Tindakan tersebut, sebagai bentuk pelindungan terhadap alam bawah laut dengan penyelarasan terhadap alam dan menikmati alam tanpa menimbulkan ancaman perusakan. Selain itu, Wa Dambe juga mampu memanfaatkan sisi feminisitas dalam dirinya sebagai bentuk sebagai sikap konservatif terhadap alam dengan kemampuan membaca tanda-tanda alam dan memperkirakan jarak dan waktu tempuh perjalanan laut dan rasi bintang. Selanjutnya, bentuk konservasi yang dilakukan tokoh Anisa, berupa tindakan pemanfaatan, perlindungan dan pelestarian lingkungan dengan menghasilkan makanan hasil olahan alam dan melestarikan makanan lokal. Pemanfaatan dan pelestarian terhadap alam menjaga ketahanan pangan dilakukan oleh tokoh Wa Dambe yang memanfaatkan kemampuannya untuk mengolah beragam hasil alam. Dalam hal tersebut, buah diolah menjadi minuman, hasil laut diolah sebagai makanan dan ubi dimafaatkan sebagai makanan pengganti nasi.Pemanfaatan sumber daya alam dilakukan sacara arif dan bijaksana dilakukan tokoh Wa Dambe dan Wa Tanihi. Wa Dambe dan Wa Tanihi memfaatkan beras dan rempah yang merupakan hasil alam untuk mebuat bedak dingin, bahan kecantikan alami, dan menetralisir penggunaan zat kimia berbahaya bagi alam dan tubuh manusia.

\section{DAFTAR PUSTAKA}

Hardiningtyas, P. R. (2016). Resistansi Perempuan Papua di Lingkungannya 
dalam Roman Isinga Karya Dorothea Rosa Herliany. Aksara, 28(2), 143-153. https://doi.org/10.29255/aksara.v28i2.1 27.

Mies, M., Shiva, V., \& Shiva, V. (2014). Ecofeminismo: Teoría, crítica y perspectivas. Icaria.

Moleong, L. J. (2019). Metodologi Penelitian Kualitatif. Bandung: PT. Remaja Rosda Karya.

Novitasari, I. (2018). Perjuangan Tokoh Jurmini Terhadap Penyelamatan Pulau Bungin dalam Novel dari Rahim Ombak Karya Tison Sahabuddin Bungin: Kajian Ekofeminisme SosialTransformatif. Jurnal Sapala, 5(1), 111.

Oedji, Dedi. (2012). Novel Chemistry Cinta di Wakatobi. Jakarta: PT. Gramedia.

Setyorini, N. (2017). Perempuan dan Kejahatan Cyber: Analisis Wacana Kritis Pemberitaan Perempuan di Media Sosial. An1mage.

Solichin, M. B. (2018). Ketika Alam dan Perempuan Lembah Baliem Diperkosa oleh Antroposentrisme Kapitalis: Kajian Ekofeminisme dalam Novel Tanah Tabu. Semiotika: Jurnal Ilmu Sastra Dan Linguistik, 19(1), 41-50. https://doi.org/10.19184/semiotika.v19i 1.7049

Sudikan, S.Y. 2016. Ekologi Sastra. Lamongan: CV. Pustaka Ilalang Group.

Warren, K. J. (1987). Feminism and Ecology: Making connections. Environmental Ethics, 9(1), 3-20. https://doi.org/10.5840/enviroethics 198 79113.

Wiyatmi, M. S., \& Swatikasari, E. (2017). Ekofeminisme: Kritik Sastra Berwawasan Ekologis dan Feminis. Yogyakarta: Cantrik Pustaka.
Wulan, T. R. (2007). Ekofeminisme transformatif: Alternatif kritis mendekonstruksi relasi perempuan dan lingkungan. Sodality:Jurnal Sosiologi Pedesaan, 1(1), 105-130. https://doi.org/10.22500/sodality.v1i1.5 935

Wuriyani, E. P. (2017). Kerusakan Alam Sebagai Bentuk Penindasan Baru Terhadap Perempuan (Kajian Ekofeminisme Dalam Sastra). Proceedings The 1st International Conference on Education, Language, and Arts (ICELA), 1(1), 2149-2157. http://digilib.unimed.ac.id/id/eprint/399 60 